\title{
Economic Evaluation of Combined Generation and Storage Solutions in Low Voltage Portuguese Consumers
}

\author{
Rúben A. Soares \\ INESC TEC, Campus da FEUP, \\ Rua Dr.Roberto Frias, 378, 4200-465 Porto, Portugal \\ rasoares@inescporto.pt
}

\author{
João Tomé Saraiva \\ INESC TEC and FEUP/DEEC \\ Rua Dr. Roberto Frias, 378, 4200-465 Porto, Portugal \\ jsaraiva@fe.up.pt
}

\begin{abstract}
This paper presents the results that were obtained in the scope of a consultancy study developed by INESC TEC for a Portuguese distribution network company to evaluate the interest of installing storage devices and $P V$ panels in $L V$ installations. We conducted simulations for consumers with annual demands of $5000 \mathrm{kWh}$ (Type $\mathrm{C}$ consumers) and 7500 kWh (Type B consumers). In general, we concluded that the installation of storage devices is still of little economic interest given the current investment level and the tariffs paid to inject electricity in the networks. The largest NPV values were obtained when only installing PV panels in Type B consumers, the larger ones, and selling the surplus energy to the network.
\end{abstract}

Index Terms-- Self-Consumption, PV, Storage, Lithium-ion Battery, Economic feasibility, NPV.

\section{INTRODUCTION}

\section{A. Energy Storage Evolution}

This paper reports the main results obtained in the scope of a consultancy study developed by INESC TEC to a Portuguese utility, EDP Distribuição, in order to evaluate the impact of energy storage solutions connected to low voltage (LV) Portuguese installations. On the other hand, this paper extends the results reported in a previous paper presented on EEM2015, in which this impact was evaluated for small consumers, termed as Type $C$ consumers. In this paper, we are now including results for larger LV consumers, termed as Type B, as well as comparisons between the results obtained for these two classes of consumers.

In recent years, energy storage technologies have gained an increasing relevance namely for generation and distribution companies, system operators, retailers, manufactures, researchers and state agencies. There are a significant number of potential advantages associated to the introduction of these technologies in power system, for instance, related with the possibility of enlarging the share of generation coming from volatile sources as wind and photovoltaic (PV) units, voltage support, transmission congestion relief and possible deferral of investment in transmission and distribution assets. However, introducing energy storage systems in power systems brings several challenges. In the first place, the investments in these units should be cost effective, to enable economic growth, increase competitiveness and to make energy available for all. Secondly, there are policy and regulatory issues for instance related with market design, with the legal and regulatory framework designed for storage units and in a general way to establish who can do what when speaking about storage [1]. In fact, storage units can be used for a variety of purposes, namely to store energy produced by a wind park, to supply peak demand thus reducing congestion in network equipments, for arbitrage purposes profiting from the spread of the market peak and off peak prices. Some of these uses can be included in network activities, some others are typical of retailers or consumers while some others can be developed by generation companies. This ultimately means that the regulatory and legal design should establish how each agent can use storage devices, namely generation companies, network providers, retailers and consumers thus determining the business models to be adopted. On the other hand, the evolution of power systems in recent years suggest that they will evolve to more decentralized models and to increase the local energy autonomy together with a larger emphasis on demand side management tools.

In Portugal the number of micro and small electricity producers has been increasing profiting from the opportunities opened by new legislation allowing using the produced energy for self-consumption and selling the excess to the grid. The dissemination of microgeneration solutions on LV, end user installations, namely PV units also contributes to the emergence of solutions enabling a more effective management of the generated energy increasing the operation flexibility of these microgeneration units.

In this scope, the Decree no 153/2104 passed in Portugal in the October 20, 2014, frames the operation of generation units for self-consumption and its provisions are important to establish several assumptions adopted in the simulations detailed in the paper. The most relevant provisions of this Decree are listed below [2]:

- The energy generated in the installation where the Unit for Self-Consumption Generation, USCG, is located can be consumed locally and eventual 
excessive energy regarding local demand can be injected in the distribution network (article 7);

- The USCG shall be designed so that the generated energy is close to the local demand (article 8);

- The instantaneous excessive generated energy can be injected in the distribution network and shall be paid at the wholesale market price considering a reduction of $10 \%$ in order to compensate the costs due to the injection of energy in LV networks (article 24);

Considering the rapid evolution of micro generation and storage solutions, this paper reports the results of the economic evaluation of installing PV systems together with storage devices in LV end user installations. In this study, we analysed several scenarios related with different business models considering the installation of PV panels alone, of PV panels together with storage and the possible use of storage equipment for price arbitrage purposes. These simulations were conducted for Type C (annual demand up to $7140 \mathrm{kWh}$ ) and Type B (annual demand larger than $7140 \mathrm{kWh}$ ) in order to investigate how the demand level impacts on the economic performance of each possible solution. In particular, we used a Type $\mathrm{C}$ consumer with an annual demand of $5000 \mathrm{kWh}$ and a Type B consumer with an annual demand of $7500 \mathrm{kWh}$.

Having in mind these ideas and objectives, this paper is structured as follows. After the Introduction, Section II gives an overview on energy storage solutions as well as their typical applications. Section III describes the adopted methodology to conduct the economic evaluation mentioned above and Section IV describes the results that were obtained for Types B and C consumers. Finally. Section V describes works to develop in the future and Section VI outlines the main conclusions.

\section{STORAGE SOLUTIONS}

The installation of storage equipments in power systems is justified by several reasons but the most relevant one is perhaps to increase its operation and management flexibility. Among available storage technologies, pumping hydro is used for several years and it is still the storage technology that by far has the largest capacity share. In recent years, there is a renewed interest for pumping hydro as a way to accommodate volatile generation (from wind and PV units). As an example, by the end of 2014, Portugal had an installed generation capacity of $17.834 \mathrm{MW}$, from which $5269 \mathrm{MW}$ in large hydro stations (1300 MW in pumping stations), 415 MW in small hydros below 10 MVA, $4541 \mathrm{MW}$ in wind parks and $396 \mathrm{MW}$ in PV units. Wind parks correspond to about $25 \%$ of the total capacity thus justifying recent and ongoing investments in pumping hydro stations.

Apart from traditional pumping hydro units, there is currently a wide range of storage technologies that convert electricity in other types of energy (e.g., mechanic, chemical, electrochemical, and thermal), that is then converted back to electricity. It is expected that some of these technologies get sufficiently mature to be successfully introduced in the market enabling their wide spread deployment.

As mentioned in the Introduction, storage devices can be installed in view of several possible applications as price arbitrage, provision of reserve services, enabling a larger integration of units using volatile primary resources (as wind and PV units), deferral of investments in distribution networks and to help managing these networks in terms of reducing losses and improving the voltage profile [3]. Apart from this wide number of possible applications, it is also true that storage technologies have very different characteristics (in terms of unit investment and operation costs, response time, discharge rate, number of cycles, ...) which means that the success of installing and using a specific technology very much depends on its appropriate choice in view of its application. This means is important to identify clearly the advantages and disadvantages of each technology having in mind its possible application area and objectives to achieve. In order to help selecting the most appropriate technology, storage devices can be grouped in the next three main areas:

- Large scale storage (LS), devices directly connected to the transmission system;

- Small scale storage (SS), devices directly connected to the distribution system or end user installations;

- Large and small scale storage (LSS), equipments that can be connected both to the transmission or distribution networks and to end user installations.

In this scope, and according to the available literature, Table I provides a classification of storage technologies currently available indicating for each of them its most typical application area (LS, SS or LSS) as defined above.

TABLE I. Energy storage technologies and correspondent application area

\begin{tabular}{lc}
\hline Storage technology & Application Area \\
\hline Pumping Hydro & LS \\
Compressed Air & LS \\
Power to Gas & LS \\
Hydrogen & LS \\
Thermal (e.g., Concentrated Solar Power) & LS \\
Super capacitor & SS \\
Superconducting Magnetic & SS \\
Hydrogen (e.g., Hydrogen Fuel Cells) & SS \\
Thermal (e.g., District Heating) & SS \\
Conventional Batteries (Lead-Acid, Nickel & LSS \\
Based, Lithium - ion) & LSS \\
Flow Batteries & LSS \\
High Temperature Batteries & LSS \\
Flywheel & \\
\hline
\end{tabular}

\section{DEVEloped Methology}

\section{A. General Aspects}

As mentioned in the Introduction, it was our purpose to analyse the economic performance of several business models involving the installation of PV and storage units in LV end user installations. We used demand and PV microgeneration profiles that are publicly available for 2014 in the web site of the Portuguese Energy Regulatory Agency, ERSE [4, 5] on a 15 min discretization basis. For the demand, we used profiles for Types B and C consumers. Profile B is for consumers with an annual demand larger than $7140 \mathrm{kWh}$, and Profile $\mathrm{C}$ corresponds to consumers with a demand below that level. Thus, we used an annual demand of $7500 \mathrm{kWh}$ for Type B and $5000 \mathrm{kWh}$ for Type C consumers. Assuming these values, we admitted that Type B consumers have a contracted power higher than $6.9 \mathrm{kVA}$ and Type $\mathrm{C}$ have a contracted power 
below $6.9 \mathrm{kVA}$. We also admitted that these consumers have a supply contract with the Regulated Retailer so that their tariffs are entirely publicly available since they are set by the Regulatory Agency. These consumers can select one of the four Time of Use, ToU, tariffs with two or three time steps and each of them with a daily or a weekly cycle. Furthermore, we admitted that these tariffs are updated along the period under analysis at $1.5 \%$ above the expected inflation rate, so that a total increase of $2.5 \%$ /year was used in the simulations.

Given that our focus is on small-scale storage, we selected Lithium-ion batteries because of their maturity and performance. Table II presents the main technical characteristics of the batteries used in this study. We also admitted that going from complete discharge till a full charge state takes 3 hours and the price of Lithium-ion batteries was set at $200 € / \mathrm{kWh}$ as expected in [6] for 2020. For the PV panels we used $1640 € / \mathrm{kWp}$ and this value includes installation and electronic control equipments costs.

TABLE II. Characteristics of the used Lithium-ion batteries.

\begin{tabular}{lc}
\hline \multicolumn{2}{c}{ Lithium-ion battery } \\
\hline Storage capacity ( & $1-10 \mathrm{kWh}$ \\
Maximum charge/discharge rate & $50 \%$ \\
Depth of Discharge (DOD) & $85 \%$ \\
Total system efficiency & $0.1 \%$ day \\
Storage self-discharge & \\
\hline
\end{tabular}

The economic performance of investing in storage equipments and / or PV panels was assessed using the Net Present Value, NPV, given by (1).

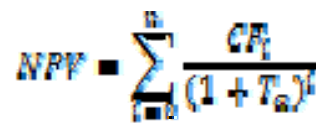

In this expression, $\mathcal{C}$ i is the Cash-Flow for year i and $T_{a}$ is the discount rate. In the simulations we used $8 \%$ for the discount rate and the evaluation horizon was set as the smaller of the life times of the equipments used in each simulation. If we are just considering PV panels, then we used 20 years. If the investment includes Lithium-ion batteries, the horizon is reduced to 12 years.

Regarding the simulations, for each 15 min time step of the horizon we get the value of the PV generation and of the demand from the profiles mentioned before. Then, we considered two situations as follows:

i) No storage device is installed - the amount of PV generation is compared with the LV demand. If there is an excess, then Case 2 admits selling it back to the network.. If local generation is insufficient, then the grid supplies the difference;

ii) A storage device is installed - in this case we take into account the charging level of the battery, the hour of the day and the assumptions assumed in each business case related with the management of the battery to decide to store electricity, to supply the demand or to buy from the network profiting from lower price periods.

Once the simulation horizon is completed, we estimate the yearly cash flows using the yearly energy values bought from the grid and sold to the grid. These amounts are then compared with the value of the energy bought from the grid without storage and PV panels. The differences of these yearly cash flows are used to compute the NPV using (1).

\section{B. Case Studies}

The NPV was calculated for several scenarios that are described below. Case 1 only considers PV panels, Case 2 emulates the Portuguese self-consumption legislation and Cases 3 and 4 represent different business models foreseen in the future regarding the installation of PV panels and / or storage units in LV. The mentioned scenarios are as follows:

- Case 1 - installation of PV panels in order to supply the LV demand. In this case we are not considering the possibility of selling the instantaneous generation excess to the network;

- Case 2 - the installation of PV panels to supply the LV demand and possibility of selling the instantaneous excess generation to the grid, according to the legislation in Section I. This energy is paid at the wholesale market price reduced by $10 \%$. We used the average price of the MIBEL for 2012 of $48.07 € / \mathrm{MWh}$ reduced by $10 \%$, as indicated above;

- Case 3 - installation of PV panels and batteries. PVs are used to supply the local demand and the excess generation is stored in the battery for later use or when local generation is more reduced than local demand. Therefore, the combination of these two equipments aims at reducing the energy dependency from the grid.

- Case 4 - this case just considers the installation of a storage system to buy and store energy in off peak hours beyond the local demand. The stored energy is used for self-consumption in peak hours. In these periods, if the stored energy is insufficient to supply the demand, the rest is bought from the grid.

As detailed in Section IV, we considered Types B and C consumer profiles as well as different values for the capacity of the batteries and of the PV units.

\section{RESUlts OF THE SimUlations}

\section{A. Case 1}

Tables III and IV display the values obtained for the NPV for each time of use tariff and for capacities of the PV panels from 1 to $10 \mathrm{kWp}$ for Types $\mathrm{C}$ and $\mathrm{B}$ consumers.

\begin{tabular}{|c|c|c|c|c|}
\hline $\begin{array}{c}\mathrm{PV} \\
(\mathrm{kWp})\end{array}$ & 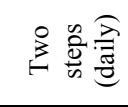 & 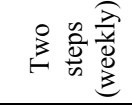 & 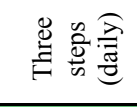 & 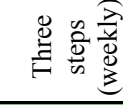 \\
\hline 1 & 1554,75 & 1233,62 & 1430,05 & 1155,00 \\
\hline 2 & 777,47 & 353,84 & 597,76 & 245,65 \\
\hline 3 & $-586,17$ & $-1038,89$ & $-780,32$ & $-1162,73$ \\
\hline 4 & $-2080,21$ & $-2543,55$ & $-2281,55$ & $-2677,50$ \\
\hline 5 & $-3624,72$ & $-4092,09$ & $-3830,10$ & $-4233,16$ \\
\hline 6 & $-5194,80$ & $-5663,74$ & $-5402,58$ & $-5810,10$ \\
\hline 7 & $-6781,29$ & $-7250,95$ & $-6990,35$ & $-7401,34$ \\
\hline 8 & $-8375,24$ & $-8845,37$ & $-8584,98$ & $-8999,22$ \\
\hline 9 & $-9979,02$ & $-10448,85$ & $-10188,96$ & $-10605,47$ \\
\hline 10 & $-11589,65$ & $-12059,03$ & $-11799,42$ & $-12217,84$ \\
\hline
\end{tabular}


TABLE IV. Case 1 - Type B - NPV for different PV capacities and tariffs.

\begin{tabular}{|c|c|c|c|c|}
\hline $\begin{array}{c}\mathrm{PV} \\
(\mathrm{kWp})\end{array}$ & 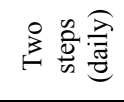 & 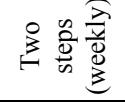 & 导总怘 & 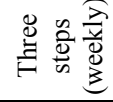 \\
\hline 1 & 1998,39 & 1640,32 & 1856,53 & 1538,87 \\
\hline 2 & 2572,64 & 2013,01 & 2311,02 & 1859,30 \\
\hline 3 & 1768,54 & 1134,23 & 1452,76 & 949,42 \\
\hline 4 & 506,14 & $-158,66$ & 169,87 & $-362,96$ \\
\hline 5 & $-915,47$ & $-1595,31$ & $-1262,14$ & $-1813,16$ \\
\hline 6 & $-2407,85$ & $-3095,57$ & $-2761,32$ & $-3323,66$ \\
\hline 7 & $-3939,41$ & $-4631,14$ & $-4297,35$ & $-4867,49$ \\
\hline 8 & $-5491,71$ & $-6185,94$ & $-5853,03$ & $-6429,24$ \\
\hline 9 & $-7063,05$ & $-7758,09$ & $-7426,66$ & $-8006,88$ \\
\hline 10 & $-8645,13$ & $-9340,95$ & $-9010,22$ & $-9594,29$ \\
\hline
\end{tabular}

For a Type $\mathrm{C}$ consumer the best option is to install $\mathrm{PV}$ panels with a capacity of $1 \mathrm{kWp}$. The largest NPV value is obtained for a two steps tariff (dual tariff) with a daily cycle $(\mathrm{NPV}=1554.75 €)$. For a Type B consumer with a yearly demand of $7500 \mathrm{kWh}$ the best choice is to install $2 \mathrm{kWp} \mathrm{PV}$ panels. The largest NPV value is obtained for a ToU tariff with two steps with a daily cycle $(\mathrm{NPV}=2572.64 €)$.

\section{B. Case 2}

According to the legislation mentioned in Section I, the power of the USGC should be selected so that the generated energy is close to the local demand. Assuming that the PV panels operate 1700 hours/year, a Type $C$ consumer needs a PV system with a capacity of $2.5 \mathrm{kWp}$ that corresponds to an annual generation of $4250 \mathrm{kWh}$. For Type B consumers the capacity of the PV system can go up to $4 \mathrm{kWp}$. Using again 1700 hours/year of operation, the panels generate $6800 \mathrm{kWh}$, below the $7500 \mathrm{kWh}$ of yearly local demand. Let us remind that in this case the panels supply the local demand and sell the instantaneous excess generation to the grid. Tables $\mathrm{V}$ and VI display the NPV values for Types $\mathrm{C}$ and $\mathrm{B}$ consumers.

TABLE V. Case 2 - Type C - NPV for different PV capacities and tariffs.

\begin{tabular}{|c|c|c|c|c|}
\hline $\begin{array}{c}\mathrm{PV} \\
(\mathrm{kWp})\end{array}$ & 总总畜 & 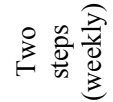 & 总总全 & 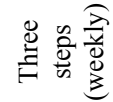 \\
\hline 0,5 & 963,43 & 789,92 & 897,43 & 743,01 \\
\hline 1 & 1629,75 & 1308,62 & 1505,05 & 1230,00 \\
\hline 1,5 & 1615,63 & 1227,24 & 1454,88 & 1132,21 \\
\hline 2 & 1397,47 & 973,84 & 1217,76 & 865,65 \\
\hline 2,5 & 1069,72 & 627,27 & 881,27 & 510,16 \\
\hline
\end{tabular}

TABLE VI. Case 2 - Type B - NPV for different PV capacities and tariffs.

\begin{tabular}{|c|c|c|c|c|}
\hline $\begin{array}{c}\mathrm{PV} \\
(\mathrm{kWp})\end{array}$ & 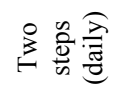 & 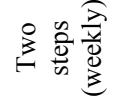 & 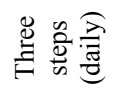 & 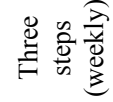 \\
\hline 0,5 & 999,33 & 820,24 & 928,39 & 769,51 \\
\hline 1 & 1998,44 & 1640,38 & 1856,59 & 1538,92 \\
\hline 1,5 & 2691,10 & 2202,59 & 2482,29 & 2067,01 \\
\hline 2 & 2854,10 & 2294,47 & 2592,48 & 2140,76 \\
\hline 2,5 & 2784,78 & 2180,45 & 2491,28 & 2010,49 \\
\hline 3 & 2603,72 & 1969,41 & 2287,93 & 1784,60 \\
\hline 3,5 & 2319,72 & 1667,22 & 1991,31 & 1471,81 \\
\hline 4 & 1985,57 & 1320,77 & 1649,30 & 1116,47 \\
\hline
\end{tabular}

The most interesting combination is $1 \mathrm{kWp}+$ two step daily tariff for Type $\mathrm{C}$ and $2 \mathrm{kWp}+$ two step daily tariff for Type B. These combinations are the same as the ones for Case 1. In Case 2 the NPV values are larger than in Case 1 (about $75.01 €$ and $281.46 €$ for Types $\mathrm{C}$ and B consumers) is due to the extra revenue obtained in Case 2 by selling the excess generated energy. For the same capacity of the PV panels, the energy bought from the network to supply the demand is the same in both cases and so the cost of buying this energy from the retailer is also equal.

Table VII and Table VIII display the range of the number of solar hours that would be required to get the break-even of the investment for each time of use tariff and for different capacities of PV panels for the two types of consumers.

TABLE VII. Case 2 - Type C - Range of solar hours required to get the break-even of the investment.

\begin{tabular}{|c|c|c|c|c|}
\hline $\begin{array}{c}P V \\
(k W p)\end{array}$ & 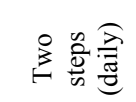 & 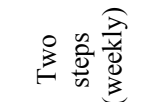 & 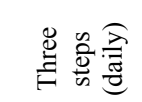 & 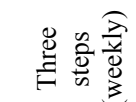 \\
\hline 0,5 & $780-790$ & $860-870$ & $810-820$ & $890-900$ \\
\hline 1 & $780-790$ & $860-870$ & $810-820$ & $890-900$ \\
\hline 1,5 & $780-790$ & $870-880$ & $810-820$ & $910-920$ \\
\hline 2 & $850-860$ & $1020-1030$ & $910-920$ & $1070-1080$ \\
\hline 2,5 & $1030-1040$ & $1250-1260$ & $1110-1120$ & $1320-1330$ \\
\hline
\end{tabular}

TABLE VIII. Case 2 - Type B - Range of solar hours required to get the break-even of the investment.

\begin{tabular}{|c|c|c|c|c|}
\hline $\begin{array}{l}\text { PV } \\
(k W p)\end{array}$ & 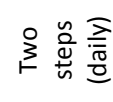 & 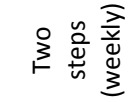 & 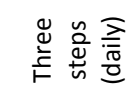 & 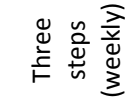 \\
\hline 0,5 & 760-770 & $840-850$ & $790-800$ & $870-880$ \\
\hline 1 & $760-770$ & $840-850$ & $790-800$ & $870-880$ \\
\hline 1,5 & $760-770$ & $840-850$ & $790-800$ & $870-880$ \\
\hline 2 & $760-770$ & $840-850$ & $790-800$ & $870-880$ \\
\hline 2,5 & $760-770$ & $860-870$ & $800-810$ & $890-900$ \\
\hline 3 & $790-800$ & $910-920$ & $840-850$ & $960-970$ \\
\hline 3,5 & $860-870$ & $1020-1030$ & $930-940$ & $1070-1080$ \\
\hline 4 & $960-970$ & $1150-1160$ & $1050-1060$ & $1220-1230$ \\
\hline
\end{tabular}

Considering the best solution obtained for the Type $\mathrm{C}$ consumer (i.e., installation of $1 \mathrm{kWp} \mathrm{PV} \mathrm{panel)} \mathrm{the} \mathrm{panel}$ shall operate from 780 to 900 hours to get the break-even of the investment. However, for Type B consumer this number reduces to 760 to 880 hours.

\section{Case 3}

Case 3 includes installing both PV panels and batteries. The excess generation from the PV panels is stored in the batteries for later use. Table IX and Table $\mathrm{X}$ display the results for a lithium-ion battery of $1 \mathrm{kWh}$ for PV panels with a capacity ranging from $0.5 \mathrm{kWp}$ to $5.0 \mathrm{kWp}$ for Types $\mathrm{C}$ and $\mathrm{B}$ consumers considering a battery price of $200 € / \mathrm{kWh}$. For storage systems of capacity larger than $1 \mathrm{kWh}$ the investment cost overrides the benefits and so the NPV values are below the ones in Table IX and Table X.

According to the results in Table IX the best option corresponds to install PV panels with a capacity of $1 \mathrm{kWp}$ together with a battery of $1 \mathrm{kWh}$. Regarding the tariff options, 
the most interesting one is once again the time of use dual tariff with daily cycle $(\mathrm{NPV}=559.08 €)$. For Type B consumers the best solution changes again due to the increase of the annual demand. Now the best solution is to install 1,5 $\mathrm{kWp}$ PV panels keeping with battery of $1 \mathrm{kWh}$. With these equipments and considering a dual tariff with daily cycle, consumer B can obtain a NPV of $1075.90 €$.

\begin{tabular}{|c|c|c|c|c|}
\hline $\begin{array}{c}\mathrm{PV} \\
(\mathrm{kWp})\end{array}$ & 总率 & 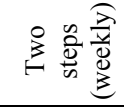 & 异造总 & 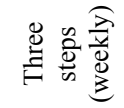 \\
\hline 0,5 & 242,95 & 118,67 & 195,94 & 85,57 \\
\hline 1 & 559,08 & 315,37 & 458,41 & 250,66 \\
\hline 1,5 & 208,53 & $-94,15$ & 76,08 & $-174,84$ \\
\hline 2 & $-363,78$ & $-695,40$ & $-506,52$ & $-787,58$ \\
\hline 2,5 & $-1043,76$ & $-1392,44$ & $-1189,09$ & $-1491,86$ \\
\hline 3 & $-1782,99$ & $-2138,77$ & $-1927,90$ & $-2242,80$ \\
\hline 3,5 & $-2543,71$ & $-2903,46$ & $-2688,17$ & $-3011,36$ \\
\hline 4 & $-3317,40$ & $-3679,55$ & $-3461,27$ & $-3790,62$ \\
\hline 4,5 & $-4099,89$ & $-4463,20$ & $-4243,35$ & $-4576,85$ \\
\hline 5 & $-4888,48$ & $-5252,52$ & $-5031,47$ & $-5368,24$ \\
\hline
\end{tabular}

TABLE X. Case 3 - Type B - NPV for different PV capacities and tariffs (Ion-lithium battery price $=200 € / \mathrm{kWh}$ ).

\begin{tabular}{|c|c|c|c|c|}
\hline \multirow[b]{2}{*}{$\begin{array}{c}\mathrm{PV} \\
(\mathrm{kWp})\end{array}$} & \multicolumn{3}{|c|}{ 年 } & \multirow[b]{2}{*}{ 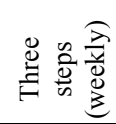 } \\
\hline & 站离离 & 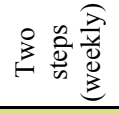 & 总总產 & \\
\hline 0,5 & 268,43 & 140,15 & 217,90 & 104,34 \\
\hline 1 & 755,63 & 498,69 & 654,13 & 426,43 \\
\hline 1,5 & 1075,90 & 710,31 & 915,96 & 606,15 \\
\hline 2 & 888,24 & 461,90 & 683,15 & 339,59 \\
\hline 2,5 & 433,81 & $-27,30$ & 204,65 & $-162,15$ \\
\hline 3 & $-120,63$ & $-606,05$ & $-364,10$ & $-752,47$ \\
\hline 3,5 & $-750,99$ & $-1252,42$ & $-1002,75$ & $-1408,91$ \\
\hline 4 & $-1455,55$ & $-1965,31$ & $-1709,52$ & $-2128,49$ \\
\hline 4,5 & $-2188,16$ & $-2703,71$ & $-2442,72$ & $-2872,24$ \\
\hline 5 & $-2937,97$ & $-3457,56$ & $-3192,89$ & $-3630,41$ \\
\hline
\end{tabular}

These results also suggest that the profitability is directly related with the level of annual demand. In order to increase the NPV a Type B consumer needs to install PV panels with a larger capacity than the Type $\mathrm{C}$ user so that their generation gets closer to its local demand. Although the dependency from the network gets reduce when installing storage systems, the benefit is in general small to offset the still large investment cost. Comparing the results in this case with the results in Case 2, the benefits are not enough to justify the investment in storage devices. For instance, when installing a $1 \mathrm{kWp} \mathrm{PV}$ panel and a $1 \mathrm{kWh}$ Lithium-ion battery the self-consumption is just increased by $1.28 \%$ regarding the installing only the PV panel. This marginal increase is due to the fact that most of the generated energy is used to supply the local demand.

The results presented above were determined admitting that in 2020 the price of the batteries reaches a level of 200 $€ / \mathrm{kWh}$. However, currently the reference price of the batteries is $500 € / \mathrm{kWh}$ and so the investment in these devices is less advantageous from an economic point of view. Table XI and Table XII display the results for a lithium-ion battery of 1 $\mathrm{kWh}$ for PV panels with a capacity ranging from $0.5 \mathrm{kWp}$ to
$5.0 \mathrm{kWp}$ for Types $\mathrm{C}$ and $\mathrm{B}$ consumers considering a battery price of $500 € / \mathrm{kWh}$.

TABLE XI. Case 3 - Type C - NPV for different PV capacities and tariffs (Ion-lithium battery price $=500 € / \mathrm{kWh}$ ).

\begin{tabular}{|c|c|c|c|c|}
\hline $\begin{array}{c}\mathrm{PV} \\
(\mathrm{kWp})\end{array}$ & 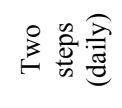 & 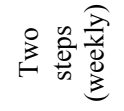 & 冚 & 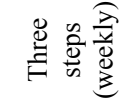 \\
\hline 0,5 & -57.05 & -181.33 & -104.06 & -214.43 \\
\hline 1 & 259.08 & 15.37 & 158.41 & -49.34 \\
\hline 1,5 & -91.47 & -394.15 & -223.92 & -474.84 \\
\hline 2 & -663.78 & -995.40 & -806.52 & -1087.58 \\
\hline 2,5 & -1343.76 & -1692.44 & -1489.09 & -1791.86 \\
\hline 3 & -2082.99 & -2438.77 & -2227.90 & -2542.80 \\
\hline 3,5 & -2843.71 & -3203.46 & -2988.17 & -3311.36 \\
\hline 4 & -3617.40 & -3979.55 & -3761.27 & -4090.62 \\
\hline 4,5 & -4399.89 & -4763.20 & -4543.35 & -4876.85 \\
\hline 5 & -5188.48 & -5552.52 & -5331.47 & -5668.24 \\
\hline
\end{tabular}

TABLE XII. Case 3 - Type B - NPV for different PV capacities and tariffs (Ion-lithium battery price $=500 € / \mathrm{kWh}$ ).

\begin{tabular}{|c|c|c|c|c|}
\hline $\begin{array}{c}\mathrm{PV} \\
(\mathrm{kWp})\end{array}$ & 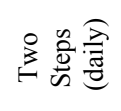 & 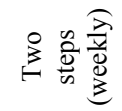 & 总总总 & 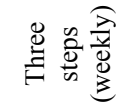 \\
\hline 0,5 & -31.57 & -159.85 & -82.10 & -195.66 \\
\hline 1 & 455.63 & 198.69 & 354.13 & 126.43 \\
\hline 1,5 & 775.90 & 410.31 & 615.96 & 306.15 \\
\hline 2 & 588.24 & 161.90 & 383.15 & 39.59 \\
\hline 2,5 & 133.81 & -327.30 & -95.35 & -462.15 \\
\hline 3 & -420.63 & -906.05 & -664.10 & -1052.47 \\
\hline 3,5 & -1050.99 & -1552.42 & -1302.75 & -1708.91 \\
\hline 4 & -1755.55 & -2265.31 & -2009.52 & -2428.49 \\
\hline 4,5 & -2488.16 & -3003.71 & -2742.72 & -3172.24 \\
\hline 5 & -3237.97 & -3757.56 & -3492.89 & -3930.41 \\
\hline
\end{tabular}

For Type B consumers it is interesting to install PV panels of $1,5 \mathrm{kWp}$ together with a battery of $1 \mathrm{kWh}$ even for the current scenario of battery price. The best option corresponds to a consumer with a two steps daily tariff (NPV $=775.90 €)$. However, for Type $\mathrm{C}$ consumers the most favorable option shows residual economic gains for some tariffs, and consequently the results are worse than for the Type B consumers. Considering the installation of $1 \mathrm{kWp}$ PV panels together with a battery of $1 \mathrm{kWh}$ and a two steps daily tariff it is possible to get a NPV of $259.08 €$.

\section{Case 4}

In this case we admit installing batteries to store energy in the off peak hours. The NPV was estimated for the capacities of the batteries indicated in Table XIII and Table XIV. The NPV values in these tables are all negative indicating that the business model associated with Case 4 is unfeasible for the battery price of $200 € / \mathrm{kWh}$ and the current tariff levels. 
TABLE XIII. Case 4 - Type C - NPV for different PV capacities and tariffs.

\begin{tabular}{|c|c|c|c|c|}
\hline $\begin{array}{c}\mathrm{PV} \\
(\mathrm{kWp})\end{array}$ & 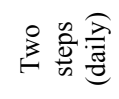 & 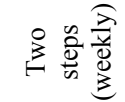 & 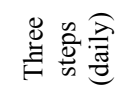 & 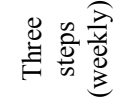 \\
\hline 0,5 & $-165,59$ & $-165,51$ & $-257,21$ & $-270,79$ \\
\hline 1 & $-331,57$ & $-331,39$ & $-514,53$ & $-541,82$ \\
\hline 1,5 & $-498,49$ & $-498,02$ & $-789,15$ & $-813,72$ \\
\hline 2 & $-666,12$ & $-669,22$ & $-1084,17$ & $-1081,06$ \\
\hline 2,5 & $-834,41$ & $-842,43$ & $-1355,15$ & $-1336,70$ \\
\hline 3 & $-1003,34$ & $-1016,79$ & $-1620,97$ & $-1590,21$ \\
\hline 3,5 & $-1172,87$ & $-1194,11$ & $-1893,99$ & $-1839,65$ \\
\hline 4 & $-1343,01$ & $-1378,32$ & $-2149,49$ & $-2087,64$ \\
\hline 4,5 & $-1513,77$ & $-1564,25$ & $-2400,33$ & $-2335,55$ \\
\hline 5 & $-1685,15$ & $-1752,40$ & $-2649,52$ & $-2583,37$ \\
\hline
\end{tabular}

TABLE XIV. Case 4 - Type B - NPV for different PV capacities and tariffs.

\begin{tabular}{|c|c|c|c|c|}
\hline $\begin{array}{c}\mathrm{PV} \\
(\mathrm{kWp})\end{array}$ & 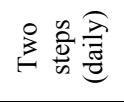 & 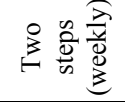 & 总总离 & 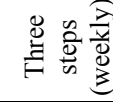 \\
\hline 0,5 & $-162,92$ & $-162,83$ & $-257,52$ & $-271,86$ \\
\hline 1 & $-325,87$ & $-325,70$ & $-515,03$ & $-543,72$ \\
\hline 1,5 & $-489,37$ & $-489,12$ & $-771,93$ & $-815,73$ \\
\hline 2 & $-653,46$ & $-652,91$ & $-1072,39$ & $-1088,37$ \\
\hline 2,5 & $-818,00$ & $-821,73$ & $-1377,42$ & $-1361,60$ \\
\hline 3 & $-982,96$ & $-991,97$ & $-1658,35$ & $-1635,35$ \\
\hline 3,5 & $-1148,34$ & $-1162,57$ & $-1921,80$ & $-1899,33$ \\
\hline 4 & $-1314,12$ & $-1333,48$ & $-2192,05$ & $-2152,76$ \\
\hline 4,5 & $-1480,30$ & $-1505,83$ & $-2466,79$ & $-2402,08$ \\
\hline 5 & $-1646,88$ & $-1681,56$ & $-2725,41$ & $-2650,96$ \\
\hline
\end{tabular}

V. FUTURE WORKS

The economic feasibility of the installation of storage devices and/or PV panels in LV consumers depends on three main factors as indicated below:

A. Demand level;

B. Electricity households prices;

C. Number of solar hours.

The main objective for future projects is to extend this economic analysis to other European countries and for that reason it is important to get information on how these three factors behave in some countries. As an illustration, Figure I presents the average number of solar hours per year and the electricity households prices in some countries/cities [7] [8].

According to the Figure 1 we can see that in countries such as France, Greece, Spain and Italy it would be interesting to carry out a similar study because they have a larger number of sun hours and electricity households prices similar to the ones in Portugal. In other countries having a more reduced number of solar hours, the economic interest of investing in storage and PV panels would also have to further analysed in order to check if that reduction does not compromise the investment.

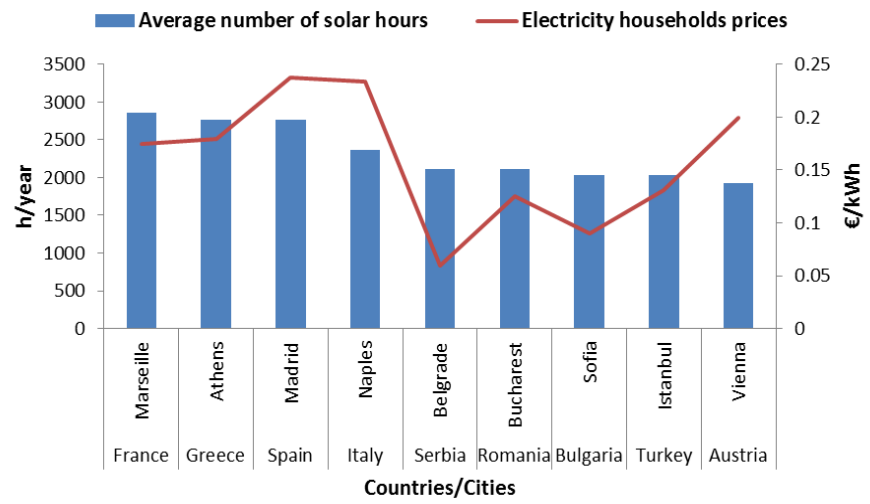

Figure 1. Average number of solar hours and electricity households prices in different countries/cities.

\section{CONCLUSIONS}

This paper reports the results of a number of simulations to evaluate the economic interest of installing storage devices and/or PV panels in LV installations. In general, we concluded that the current investment cost in Lithium-ion batteries and the current electricity tariffs turn the investment in these batteries of little interest. The largest NPV values were obtained when only installing PV panels and the economic performance grows for larger demand levels. As technologies evolve and costs most likely tend reduce, it is important to update this type of evaluations to monitor more closely the interest in investing in small-scale storage.

\section{REFERENCES}

[1] Activity Report 2014, European Association for Storage Energy. [Online]. Available: http://www.ease-storage.eu/tl files/ease-documents /3.\%20Publications/Activity\%20Report/EASE\%20Activity\%20Report $\%$ 202014 LR.pdf.

[2] Decree Law $\mathrm{n}^{\circ} 153 / 2014$, Portuguese legislation on self-consumption, October 202014 (in Portuguese)

[3] P. Medina, A.W. Bizuayehu, J.P.S. Catalão, E.M.G. Rodrigues, J. Contreras, "Electrical Energy Storage Systems: Technologies' State-ofArt, Techno-Economic Benefits and Applications Analysis", Hawaii International Conference on System Science, 2014.

[4] Entidade Reguladora dos Serviços Energéticos, "Demand profiles lor LV clients in 2014". [Online]. Available: http://www.erse.pt/pt/ electricidade/regulamentos/acessoasredesaasinterligacoes/Documents/A nexo $\% 20 \mathrm{II} \% 20 \% 20$ Perfis $\% 20$ Consumo $\% 20 \mathrm{BT} \% 202014$.xls.

[5] Entidade Reguladora dos Serviços Energéticos, "Micro and mini generation profiles for 2014". [Online]. Available: http://www.erse.pt/pt/electricidade/regulamentos/acessoasredesaasinterli gacoes/Paginas/PerfishorariosdeperdasedeconsumoemBTEBTNeIP.aspx ?master=ErsePrint.master.

[6] McKinsey, "Battery Technology". [Online]. Available: http://www.mckinsey.com/insights/energy resources materials/battery t echnology charges ahead.

[7] Total annual sunshine in European Cities - Current results. [Online]. Available:

https://www.currentresults.com/Weather/Europe/Cities/sunshine-annualaverage.php

[8] Energy price statistics - electricity and natural gas prices for both industrial and households users in EU, Eurostat. [Online]. Available: http://ec.europa.eu/eurostat/statisticsexplained/index.php/Energy price statistics 